\title{
Total Prime Labeling of Some Graphs
}

\author{
S. Meena ${ }^{1}$ and A. Ezhil ${ }^{2}$ \\ ${ }^{1}$ PG and Research Department of Mathematics, Government Arts College, C.Mutlur, \\ Chidambaram 608001. \\ ${ }^{2}$ PG and Research Department of Mathematics, Thiru Kolanjiappar Government Arts College, Vridhachalam \\ 606001 .
}

\begin{abstract}
In this paper, we investigate the existence of prime labeling for some classes of graphs. Let $G=(V, E)$ be a graph with ' $p$ ' vertices and ' $q$ ' edges. A labeling f: VUE $\{1,2,3, \ldots \ldots,(p+q)\}$ is said to admit total prime labeling if for each edge $\mathrm{e}=\mathrm{uv}$, the labels assigned to $\mathrm{u}$ and $\mathrm{v}$ are relative prime, and for eath trtex of degree atleast two, the greatest common divisor of the labels on the incident edges is one. A graph which admits total prime labeling is called total prime graph. We prove that the graphs Wheel $\left(\mathrm{W}_{\mathrm{n}}\right), \mathrm{Gear}\left(\mathrm{G}_{\mathrm{n}}\right)$, Carona $\left(\mathrm{C}_{4 \mathrm{c}} \mathrm{K}_{5}\right)$, Triangular book $\left(\mathrm{B}_{3}{ }^{\mathrm{n}}\right)$, Splitting graph of a star $\left(\mathrm{K}_{1, \mathrm{n}}\right)$, Double comb and Planter graph $\left(\mathrm{R}_{\mathrm{n}}\right)$ are all total prime graphs.
\end{abstract}

Keywords: Prime labeling, vertex prime labeling, total prime labeling, splitting, planter.

\section{INTRODUCTION:}

Here, we consider only the graphs which are finite, simple and undirected graphs. A graph $\mathrm{G}=(\mathrm{V}(\mathrm{G})$, $E(G)$ ) where $V(G)$ denotes the vertex set and $E(G)$ denotes the edge set. The order and size of the graph $\mathrm{G}$ are denoted by ' $\mathrm{p}$ ' and ' $\mathrm{q}$ ' respectively. Graph labeling where the vertices and edges are assigned real values with satisfying some conditions. Two integers are said to be relatively prime means the greatest common divisor is one.

For all other terminology and notations in graph theory, we follow Harary [1]. The notion of prime labeling was introduced by Rojer Entringer and was discussed in a paper by Tout [2] and vertex prime labeling was discussed in a paper by Deretesky [3].

Prime labeling and vertex prime labeling are already introduced. Combining these two results a new labeling called a total prime labeling was defined by Kala and Ramasubramanian [4] and they proved that the graphs $P_{n}$, cycle $C_{n}$, star $K_{1, n}$, Helm $H_{n}$ and comb are total prime labeling graphs.

\section{Definition 1.1}

Let $G=(V, E)$ be a graph with ' $p$ ' vertices, A labeling $f: V(G) \quad\{1,2,3, \ldots \ldots . p\}$ is said to be as prime labeling if for each edge $\mathrm{e}=$ uv the labels assigned to $\mathrm{u}$ and $\mathrm{v}$ are relatively prime. A graph which admits prime labeling is called prime graph.

\section{Definition 1.2}

Let $\mathrm{G}=(\mathrm{V}, \mathrm{E})$ be a graph with ' $\mathrm{p}$ ' vertices and ' $\mathrm{q}$ ' edges. A labeling $\mathrm{f}: \mathrm{E}(\mathrm{G}) \quad\{1,2, \ldots \ldots \mathrm{q}\}$ is said to be vertex prime labeling if for each vertex of degree atleast two the greatest common divisor of the labels on its incident edges is one.

Definition 1.3
Let $\mathrm{G}=(\mathrm{V}, \mathrm{E})$ be a graph with 'p' vertices and ' $q$ ' edges.

A labeling f: V U E $\{2,3, \ldots . .(p+q)\}$ is said to be total prime labeling if,

(i) for each edge $\mathrm{e}=\mathrm{u} v$, the labels assigned to $\mathrm{u}$ and $\mathrm{v}$ are relatively prime.

(ii) for each vertex of degree atleast two, the gcd of the labels on the incident edge is one.

A graph which admits total prime labeling is called total prime graph.

\section{Definition 1.4}

The gear graph $\mathrm{Gn}$ is, the graph obtained from wheel $\mathrm{W}_{\mathrm{n}}=\mathrm{C}_{\mathrm{n}}+\mathrm{K}_{1}$ by subdividing each edge incident with the apex vertex once.

\section{Definition 1.5}

The carona product of $\mathrm{C}_{5}$ and $\mathrm{K}_{5}$ is the graph obtained from a cycle $\mathrm{C}_{\mathrm{n}}$ by attaching " $\mathrm{m}$ " new pendant edges at each vertex of cycle.

\section{Definition 1.6}

One edge union of cycles of same length is called a book. The common edge is called base of the book. If we consider $n$ copies of cycles of length $t \geq 3$, the book is denoted by $B_{t}{ }^{n}$. If $n=3$ the book is called triangular book graph.

\section{Definition 1.7}

A graph obtained by attaching a single pendent edge to each vertex of a path $\mathrm{P}_{\mathrm{n}}=\mathrm{v}_{1}, \mathrm{v}_{2}, \mathrm{v}_{3} \ldots \ldots \mathrm{v}_{\mathrm{n}}$ is called a comb.

\section{Definition 1.8}




\section{Available online at www.ijrat.org}

For each vertex $v$ of a graph $G$, take a new vertex $u$. Join $u$ to all the vertices of $G$ adjacent to $v$. The graph $S(G)$ obtained is called splitting graph of G.

\section{Definition 1.9}

\section{Main Results:}

Theorem 2.1: The wheel graph $\mathrm{W}_{\mathrm{n}}$ is a total prime graph.

Proof: Let $\mathrm{G}$ be the wheel graph.

Let $\mathrm{V}\left(\mathrm{W}_{\mathrm{n}}\right)=\left\{\mathrm{v}_{1}, \mathrm{v}_{2}, \mathrm{v}_{3}, \ldots \ldots \mathrm{v}_{\mathrm{n}}, \mathrm{v}_{\mathrm{n}+1}\right\}$ and

$$
\mathrm{E}\left(\mathrm{W}_{\mathrm{n}}\right)=\left\{\mathrm{v}_{1} \mathrm{v}_{\mathrm{i}+1} / 1 \leq \mathrm{i} \leq \mathrm{n}\right\} \quad \mathrm{U}\left\{\mathrm{v}_{\mathrm{i}} \mathrm{v}_{\mathrm{i}+1} / 2 \leq \mathrm{i} \leq \mathrm{n}\right\} \mathrm{U}\left\{\mathrm{v}_{\mathrm{n}+1} \mathrm{v}_{2}\right\}
$$

The total number of vertices $\mathrm{p}$ is $\mathrm{n}+1$ and the total number of edges $\mathrm{q}$ is $2 \mathrm{n}$.

Here, $p+q=3 n+1$

Define a labeling f: VUE $\quad\{1,2,3,4, \ldots \ldots . .(3 n+1)\}$ by

$$
\begin{aligned}
& \mathrm{f}\left(\mathrm{v}_{1}\right)=1 \\
& \mathrm{f}\left(\mathrm{v}_{2}\right)=2 \\
& \mathrm{f}\left(\mathrm{v}_{\mathrm{i}}\right)=2 \mathrm{i}-3 \text { for } 3 \leq \mathrm{i} \leq \mathrm{n}+1 \\
& \mathrm{f}\left(\mathrm{e}_{\mathrm{i}}\right)=2+2 \mathrm{i} \text { for } 1 \leq \mathrm{i} \leq \mathrm{n}-1 \\
& \mathrm{f}(\text { ei })=n+1+\mathrm{i} \text {; for } \mathrm{n} \leq \mathrm{i} \leq 2 \mathrm{n} .
\end{aligned}
$$

According to this pattern, the

$$
\begin{aligned}
& \operatorname{gcd}\left\{\mathrm{f}\left(\mathrm{v}_{1}\right), \mathrm{f}\left(\mathrm{vi}_{+1}\right)\right\}=\operatorname{gcd}\{(1,1+\mathrm{i})\}=1,1 \leq \mathrm{i} \leq \mathrm{n} . \\
& \operatorname{gcd}\left\{\mathrm{f}\left(\mathrm{vi}_{\mathrm{i}}\right), \mathrm{f}\left(\mathrm{vi}_{1+1}\right)\right\}=\operatorname{gcd}\{(\mathrm{i}, \mathrm{i}+1)\}=1,2 \leq \mathrm{i} \leq \mathrm{n} . \\
& \operatorname{gcd}\left\{\mathrm{f}\left(\mathrm{vn}_{\mathrm{n}+1}\right), \mathrm{f}\left(\mathrm{v}_{2}\right)\right\}=\operatorname{gcd}\{(2 \mathrm{n}-1,2)\}=1 . \\
& \operatorname{gcd}\left\{\text { all the edges incident with } \mathrm{v}_{1}\right\}=\operatorname{gcd}\{4,6,8, \ldots . .2 \mathrm{n}, 2 \mathrm{n}+1\}=1 . \\
& \operatorname{gcd}\left\{\text { all the edges incident with } \mathrm{v}_{\mathrm{i}+2}\right\}=\operatorname{gcd}\{2+2 \mathrm{i}, 2 \mathrm{n}+1+\mathrm{i}, 2 \mathrm{n}+2+\mathrm{i}\}=1 \text { for } \\
& 1 \leq \mathrm{i} \leq \mathrm{n}-1 . \\
& \operatorname{gcd}\left\{\text { all the edges incident with } \mathrm{v}_{2}\right\}=\operatorname{gcd}\{3 \mathrm{n}+1,2 \mathrm{n}+1,2 \mathrm{n}+2\}=1
\end{aligned}
$$

Thus for each edge $\mathrm{e}=\mathrm{uv}$, where $\mathrm{u}$ and $\mathrm{v}$ are relatively prime and the gcd of each vertex of degree atleast two, all the incident edges is one.

Therefore the graph wheel $\mathrm{W}_{\mathrm{n}}$ is a total prime graph.

Example:

Total prime labeling of $\mathrm{W}_{6}$ 


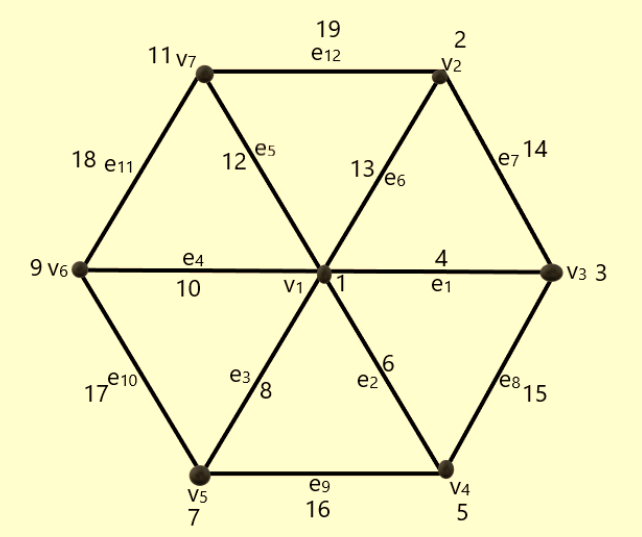

Fig.1

Theorem 2.2: The graph $\mathrm{Gear}_{\mathrm{n}}$ is a total prime graph.

Proof:

Let, $\mathrm{G}$ be the gear graph.

Let $\mathrm{V}\left(\mathrm{G}_{\mathrm{n}}\right)=\left\{\mathrm{v}_{1}, \mathrm{v}_{2}, \mathrm{v}_{3}, \ldots \ldots \ldots \mathrm{v}_{\mathrm{n}}, \mathrm{v}_{\mathrm{n}+1}, \ldots \ldots \ldots \mathrm{v}_{2 \mathrm{n}}, \mathrm{v}_{2 \mathrm{n}+1}\right\}$ and

$\mathrm{E}\left(\mathrm{G}_{\mathrm{n}}\right)=\left\{\mathrm{v}_{1} \mathrm{v}_{2 \mathrm{i}} / 1 \leq \mathrm{i} \leq \mathrm{n}\right\} \mathrm{U}\left\{\mathrm{v}_{\mathrm{i}} \mathrm{v}_{\mathrm{i}+1} / 2 \leq \mathrm{i} \leq 2 \mathrm{n}\right\} \mathrm{U}\left\{\mathrm{v}_{2 \mathrm{n}+1} \mathrm{v}_{2}\right\}$

The total number of vertex $p$ is $2 n+1$ and the total number of edges $q$ is $3 n$.

Here, $p+q=5 n+1$.

Define a bijection f: VUE

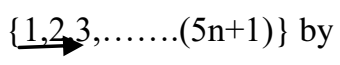

$$
\begin{aligned}
& \mathrm{f}\left(\mathrm{v}_{1}\right)=1 \\
& \mathrm{f}\left(\mathrm{v}_{\mathrm{i}+1}\right)=1+\mathrm{i} ; 1 \leq \mathrm{i} \leq 2 \mathrm{n} \\
& \mathrm{f}\left(\mathrm{e}_{\mathrm{i}}\right)=2 \mathrm{n}+1+\mathrm{i} ; 1 \leq \mathrm{i} \leq 3 \mathrm{n}
\end{aligned}
$$

According to this pattern,

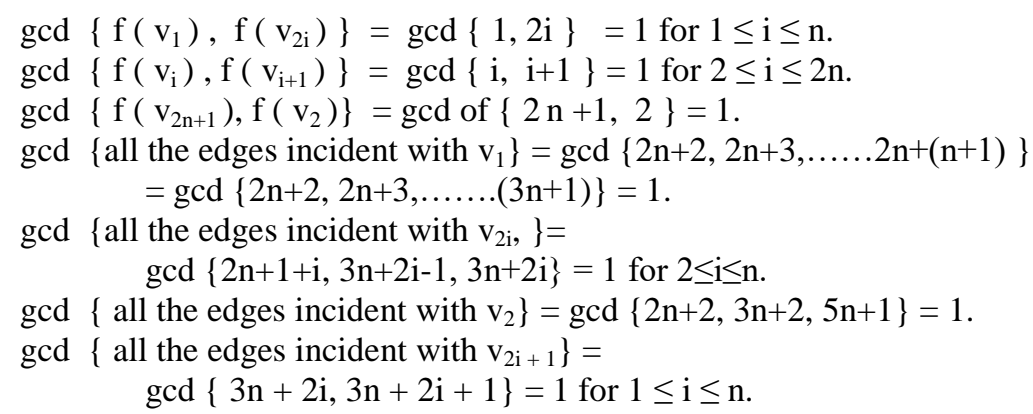

Therefore for each edge $e=u v$ the $g c d$ of $\{f(u), f(v)\}$ is one, and for each vertex degree atleast two the gcd of all the incident edges is one.

Therefore, the graph Gear $G_{n}$ is a total prime graph.

Example: Total prime labeling of Gear $\mathrm{G}_{5}$ 


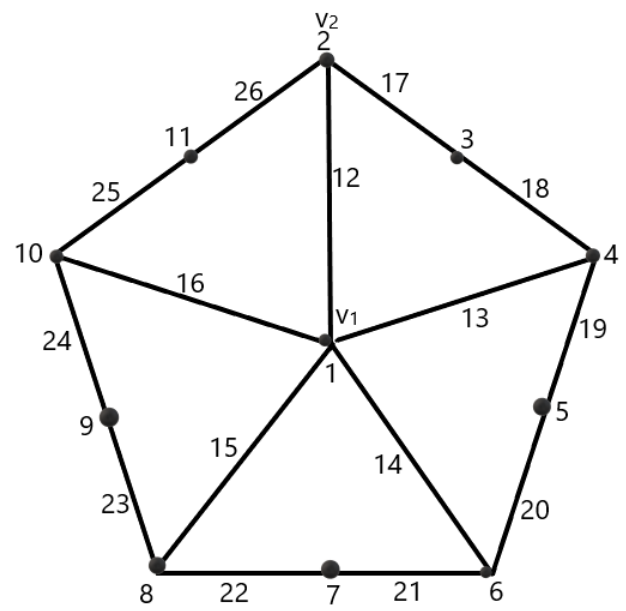

Fig. 2

Theorem 2.3: The carona product $\mathrm{C}_{4 \mathrm{c}} \mathrm{K}_{5}$ is a total prime graph.

Proof:

Let $\mathrm{G}$ be the carona graph

$$
\begin{aligned}
\mathrm{V}(\mathrm{G})= & \left\{\mathrm{v}_{\mathrm{ij}} / 1 \leq \mathrm{i} \leq 4,1 \leq \mathrm{j} \leq 6\right\} \\
\mathrm{E}(\mathrm{G})= & \left\{\mathrm{v}_{\mathrm{ij}} \mathrm{v}_{\mathrm{ij}+1} / 1 \leq \mathrm{i} \leq 4,1 \leq \mathrm{j} \leq 6\right\} \mathrm{U} \\
& \left\{\mathrm{v}_{11} \mathrm{v}_{21}\right\} \mathrm{U}\left\{\mathrm{v}_{21} \mathrm{v}_{31}\right\} \mathrm{U}\left\{\mathrm{v}_{31} \mathrm{v}_{41}\right\} \mathrm{U}\left\{\mathrm{v}_{41} \mathrm{v}_{14}\right\}
\end{aligned}
$$

The total number of vertices $\mathrm{p}$ is $\mathrm{n}(\mathrm{m}+1)$ and total number of edges $\mathrm{q}$ is $\mathrm{n}(\mathrm{m}+1)$.

Here $\mathrm{p}+\mathrm{q}=2 \mathrm{n}(\mathrm{m}+1)$.

Define a labeling f: V U E $\longrightarrow 2,3, \ldots \ldots(48)\}$ by

$\mathrm{f}\left(\mathrm{v}_{\mathrm{ij}}\right)=(5+1)(\mathrm{i}-1)+\mathrm{j}, 1 \leq \mathrm{i} \leq \mathrm{n}, 1 \leq \mathrm{j} \leq 5+1$

$f\left(e_{i j}\right)=(5+1)(4+i-1)+j$, where $m=5$ and $n=4$.

According to this pattern

$$
\begin{aligned}
& \operatorname{gcd}\left\{\mathrm{f}\left(\mathrm{v}_{11}\right), \mathrm{f}\left(\mathrm{v}_{21}\right)\right\}=\operatorname{gcd}(1,7)=1 \\
& \operatorname{gcd}\left\{f\left(v_{21}\right), f\left(v_{31}\right)\right\}=\operatorname{gcd}(7,13)=1 \\
& \operatorname{gcd}\left\{\mathrm{f}\left(\mathrm{v}_{31}\right), \mathrm{f}\left(\mathrm{v}_{41}\right)\right\}=\operatorname{gcd}(13,19)=1 \\
& \operatorname{gcd}\left\{\mathrm{f}\left(\mathrm{v}_{41}\right), \mathrm{f}\left(\mathrm{v}_{11}\right)\right\}=\operatorname{gcd}(19,1)=1 \\
& \operatorname{gcd}\left\{\text { all the edges incident with } v_{11}\right\}=\operatorname{gcd}(25,26, \ldots \ldots .30)=1 \\
& \operatorname{gcd}\left\{\text { all the edges incident with } v_{21}\right\}=\operatorname{gcd}(31,32, \ldots \ldots .36)=1 \\
& \operatorname{gcd}\left\{\text { all the edges incident with } v_{31}\right\}=\operatorname{gcd}(37,38 \ldots \ldots .42)=1 \\
& \operatorname{gcd}\left\{\text { all the edges incident with } v_{41}\right\} \quad=\operatorname{gcd}(43,44, \ldots \ldots . .48)=1
\end{aligned}
$$

Therefore, for each edge $e=u v$ the $\operatorname{gcd}$ of $\{f(u), f(v)\}$ is one, and for each vertex, the gcd of all the incident edges is one.

Therefore the graph carona $\mathrm{C}_{4 \mathrm{C}} \mathrm{K}_{5}$ is a total prime graph.

Example: total prime labeling of carona $\mathrm{C}_{4} \cdot \mathrm{K}_{5}$. 


\section{Available online at www.ijrat.org}

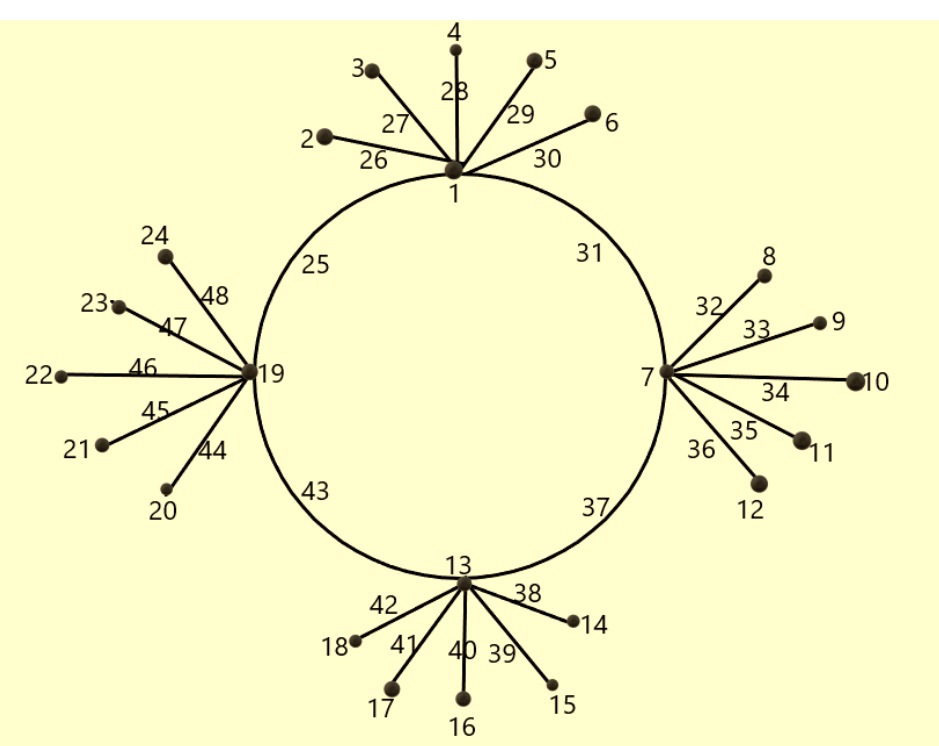

Fig.3

Theorem 2.4: The triangular book graph $\mathrm{B}_{3}^{\mathrm{n}}$ is a total prime graph if $\mathrm{n}$ is even.

Proof:

Let $\mathrm{G}$ be the triangular book graph.

$$
\begin{aligned}
& \text { Let } V\left(B^{n}{ }_{3}\right)=\left\{v_{1}, v_{2}, \ldots \ldots . v_{n}, v_{n+1}, v_{n+2}\right\} \text { and } \\
& E\left(B^{n}{ }_{3}\right)=\left\{v_{1} v_{i+1} / 1 \leq i \leq n\right\} U\left\{v_{i+1} v_{n+2} / 1 \leq i \leq n\right\} U\left\{v_{1} v_{n+2}\right\}
\end{aligned}
$$

The total number of vertices $\mathrm{p}$ is $\mathrm{n}+2$ and total number of edges $\mathrm{q}$ is $2 \mathrm{n}+1$.

Hence, $p+q=3 n+3$

Define a labeling f: VUE

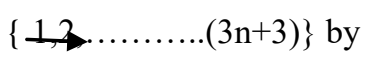

$$
\begin{aligned}
& \mathrm{f}\left(\mathrm{v}_{\mathrm{i}}\right)=\left\{\begin{array}{l}
\mathrm{i} ; 1 \leq \mathrm{i} \leq \mathrm{m}-1 \\
\mathrm{i}+1 ; \mathrm{m} \leq \mathrm{i} \leq \mathrm{n}+1 \\
\mathrm{~m} ; \mathrm{i}=\mathrm{n}+2 \\
\mathrm{f}\left(\mathrm{e}_{\mathrm{i}}\right)=\mathrm{n}+\mathrm{i} ; \mathrm{i} \leq \mathrm{i} \leq \mathrm{n}+1 .
\end{array}\right\}
\end{aligned}
$$

Where $m$ is the largest prime number such that $m \leq n+2$

According to this pattern,

$$
\begin{aligned}
& \operatorname{gcd}\left\{f\left(v_{1}\right), f\left(v_{i+1}\right)\right\}=\operatorname{gcd} \text { of }(1,1+i)=1 \text { for } 1 \leq \mathrm{i} \leq \mathrm{m}-2 \\
& \operatorname{gcd}\left\{\mathrm{f}\left(\mathrm{v}_{1}\right), \mathrm{f}\left(\mathrm{v}_{\mathrm{n}+1}\right)\right\}=(1, \mathrm{n}+2)=1 \\
& \operatorname{gcd}\left\{\mathrm{f}\left(\mathrm{v}_{\mathrm{n}+2}\right), \mathrm{f}\left(\mathrm{v}_{\mathrm{i}+1}\right)\right\}=\operatorname{gcd} \text { of }(\mathrm{m}, 1+\mathrm{i})=1 \text { for } 1 \leq \mathrm{i} \leq \mathrm{m}-2 . \\
& \operatorname{gcd}\left\{\mathrm{f}\left(\mathrm{v}_{\mathrm{n}+2}\right),\left(\mathrm{v}_{\mathrm{i}+1}\right)\right\}=1 \text { for } \mathrm{m} \leq \mathrm{i} \leq \mathrm{n}+1 \\
& \operatorname{gcd}\left\{\text { all edges incident with } \mathrm{v}_{1}\right\} \\
& \quad=\operatorname{gcd}\{\mathrm{n}+2+1, \mathrm{n}+2+3, \mathrm{n}+2+5, \ldots \mathrm{n}+2+(2 \mathrm{n}-1)\} \\
& \quad=\operatorname{gcd}\{\mathrm{n}+3, \mathrm{n}+5, \ldots \ldots \ldots 3 \mathrm{n}+1\}=1 .
\end{aligned}
$$

gcd $\left\{\right.$ all edges incident with $\left.\mathrm{v}_{\mathrm{n}+2}\right\}$

$$
\begin{aligned}
& =\operatorname{gcd}\{\mathrm{n}+3, \mathrm{n}+2+2, \mathrm{n}+2+4, \mathrm{n}+2+6, \ldots \mathrm{n}+2+2 \mathrm{n}\} \\
& =\operatorname{gcd}\{\mathrm{n}+3, \mathrm{n}+4, \mathrm{n}+6, \ldots \ldots, 3 \mathrm{n}+2\}=1
\end{aligned}
$$

gcd $\left\{\right.$ all edges incident with $\left.\mathrm{v}_{\mathrm{i}+1}\right\}$

$$
=\operatorname{gcd}(n+2 i+2, n+2 i+3)=\text { for } 1 \leq i \leq m-2 .
$$

$\operatorname{gcd}\left\{\right.$ all edges incident with $\left.v_{n+1}\right\}=\operatorname{gcd}$ of $(3 n+2,3 n+3)=1$ 


\section{Available online at www.ijrat.org}

Therefore, for each edge $e=u v$ the gcd of $\{f(u), f(v)\}$ is one, and for each vertex atleast degree two the gcd of all the incident edges is one.

Therefore the book graph $\mathrm{B}_{3}{ }^{6}$ is a total prime graph.

Example : Total prime labeling of book $\mathrm{B}_{3}{ }^{6}$

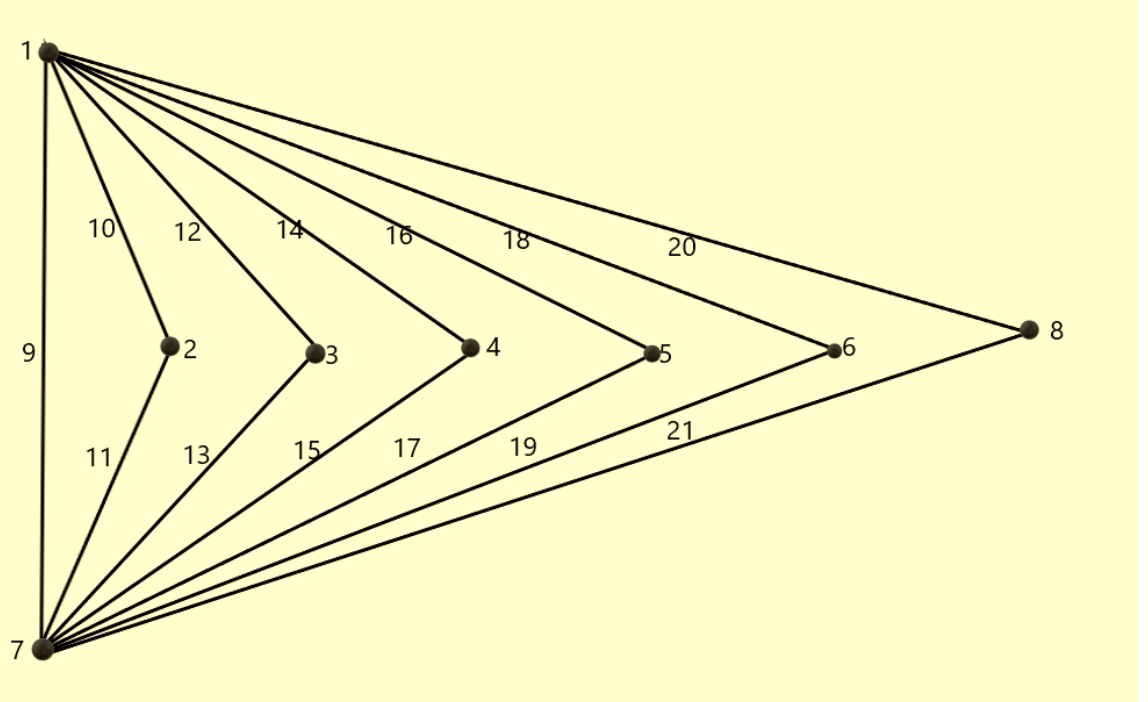

Fig.4

Theorem 2.5: Double comb $\mathrm{P}_{\mathrm{n}} \cdot \mathrm{K}_{2}$ is a total prime graph.

Proof:

Let $\mathrm{G}$ be a double comb graph

$$
\begin{aligned}
& \mathrm{V}\left(\mathrm{P}_{\mathrm{n}} \cdot \mathrm{K}_{1,2}\right)=\left\{\mathrm{u}_{1}, \mathrm{u}_{2}, \mathrm{u}_{3} \ldots \ldots \mathrm{u}_{\mathrm{n}}, \mathrm{v}_{1}, \mathrm{v}_{2}, \mathrm{v}_{3}, \ldots \ldots \ldots \mathrm{v}_{\mathrm{n}}, \mathrm{w}_{1}, \mathrm{w}_{2}, \ldots \ldots \ldots \ldots \mathrm{w}_{\mathrm{n}}\right\} \text { and } \\
& \mathrm{E}\left(\mathrm{P}_{\mathrm{n}} . \mathrm{K}_{1,2}\right)=\left\{\mathrm{u}_{\mathrm{i}} \mathrm{v}_{\mathrm{i}} / 1 \leq \mathrm{i} \leq \mathrm{n}\right\} U\left\{\mathrm{v}_{\mathrm{i}} \mathrm{w}_{\mathrm{i}} / 1 \leq \mathrm{i} \leq \mathrm{n}\right\} \mathrm{U}\left\{\mathrm{v}_{\mathrm{i}} \mathrm{v}_{\mathrm{i}+1} / 1 \leq \mathrm{i} \leq \mathrm{n}-1\right\}
\end{aligned}
$$

The total number of vertices $p$ is $3 n$ and the total number of edges $q$ is $3 n-1$.

Here $p+q=6 n-1$.

Define a labeling f: V U E

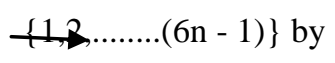

$$
\begin{aligned}
& \mathrm{f}\left(\mathrm{u}_{\mathrm{i}}\right)=3 \mathrm{i}-2 ; 1 \leq \mathrm{i} \leq \mathrm{n} \\
& \mathrm{f}\left(\mathrm{v}_{\mathrm{i}}\right)=3 \mathrm{i}-1 ; 1 \leq \mathrm{i} \leq \mathrm{n} \\
& \mathrm{f}\left(\mathrm{w}_{\mathrm{i}}\right)=3 \mathrm{i} ; \quad 1 \leq \mathrm{i} \leq \mathrm{n} \\
& \mathrm{f}\left(\mathrm{e}_{\mathrm{i}}\right)=3 \mathrm{n}+\mathrm{i} ; 1 \leq \mathrm{i} \leq 3 \mathrm{n}-1
\end{aligned}
$$

According to this pattern,

$\operatorname{gcd}\left\{\mathrm{f}\left(\mathrm{u}_{\mathrm{i}}\right), \mathrm{f}\left(\mathrm{v}_{\mathrm{i}}\right)\right\}=\operatorname{gcd}$ of $\{3 \mathrm{i}-2,3 \mathrm{i}-1\}=1$ for $1 \leq \mathrm{i} \leq \mathrm{n}$.

$\operatorname{gcd}\left\{\mathrm{f}\left(\mathrm{v}_{\mathrm{i}}\right), \mathrm{f}\left(\mathrm{w}_{\mathrm{i}}\right)\right\}=\operatorname{gcd}$ of $\{3 \mathrm{i}-1,3 \mathrm{i}\}=1$ for $1 \leq \mathrm{i} \leq \mathrm{n}$.

$\operatorname{gcd}\left\{\mathrm{f}\left(\mathrm{v}_{\mathrm{i}}\right), \mathrm{f}\left(\mathrm{v}_{\mathrm{i}+1}\right)\right\}=\operatorname{gcd}$ of $\{3 \mathrm{i}-1,3 \mathrm{i}+2\}=1$ for $1 \leq \mathrm{i} \leq \mathrm{n}-1$.

$\operatorname{gcd}\left\{\right.$ all the edges incident with $\left.v_{1}\right\}=\operatorname{gcd}$ of $\{3 n+1,3 n+2,3 n+3\}=1$

$\operatorname{gcd}\left\{\right.$ all the edges incident with $\left.v_{n}\right\}=\operatorname{gcd}$ of $\{6 n-3,6 n-2,6 n-1\}=1$

$\operatorname{gcd}\left\{\right.$ all the edges incident with $\left.v_{\mathrm{i}} / 2 \leq \mathrm{i} \leq \mathrm{n}-1\right\}$

$$
=\operatorname{gcd}\{\text { incomplete }\}
$$




\section{Available online at www.ijrat.org}

Therefore, for each edge $e=u v$ the $\operatorname{gcd}$ of $\{\mathrm{f}(\mathrm{u}), \mathrm{f}(\mathrm{v})\}$ is one, and for each vertex degree atleast two the gcd of all the incident edges is one.

Therefore $\mathrm{P}_{\mathrm{n}} . \mathrm{K}_{2}$ is a total prime graph.

Example : Total prime graph of $\left(\mathrm{P}_{4} \cdot \mathrm{K}_{1,2}\right)$

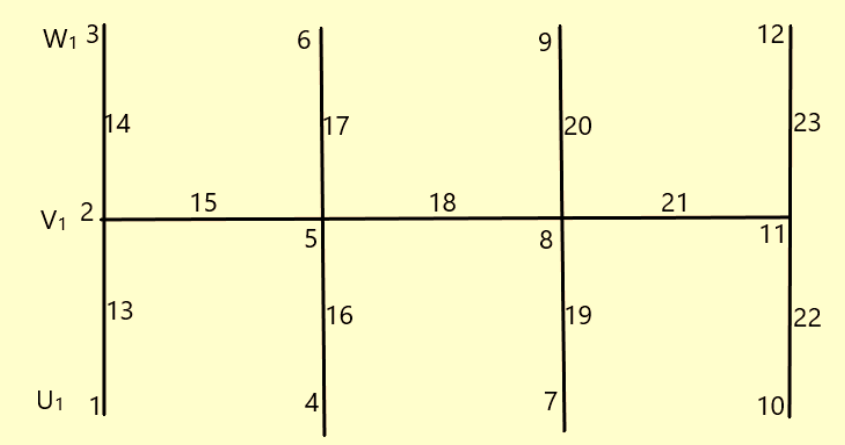

Theorem 2.6: Splitting graph of a star graph $S\left(K_{1, n}\right)$ is a total prime graph.

Proof: Let the vertices and edges of a star graph is

$$
\begin{aligned}
& \mathrm{V}(\mathrm{G})=\left\{\mathrm{v}_{1}, \mathrm{v}_{2}, \mathrm{v}_{3}, \ldots \ldots \ldots \mathrm{v}_{\mathrm{n}+1}\right\} \text { and } \\
& \mathrm{E}(\mathrm{G})=\left\{\mathrm{v}_{1} \mathrm{v}_{\mathrm{i}+1} / 1 \leq \mathrm{i} \leq \mathrm{n}\right\}
\end{aligned}
$$

Let $S(G)$ be a splitting graph of $K_{1, n}$ and $\left\{u_{1}, u_{2}, \ldots \ldots . . u_{n}, u_{n+1}\right\}$ be the newly added vertices with $K_{1, n}$ Now, $V\left\{S\left(\mathrm{~K}_{\mathrm{l}, \mathrm{n}}\right)\right\}=\left\{\mathrm{v}_{1}, \mathrm{v}_{2}, \ldots \ldots \ldots \mathrm{v}_{\mathrm{n}}, \mathrm{v}_{\mathrm{n}+1}, \mathrm{u}_{1}, \mathrm{u}_{2}, \ldots \ldots \ldots \mathrm{u}_{\mathrm{n}}, \mathrm{u}_{\mathrm{n}+1}\right\}$ and

$\mathrm{E}\left\{\mathrm{S}\left(\mathrm{K}_{1, \mathrm{n}}\right)\right\}=\left\{\mathrm{v} \mathrm{v}_{\mathrm{i}} / 1 \leq \mathrm{i} \leq \mathrm{n}\right\} \mathrm{U}\left\{\mathrm{v}_{\mathrm{i}} \mathrm{u} / 1 \leq \mathrm{i} \leq \mathrm{n}\right\} \mathrm{U}\left\{\mathrm{u} \mathrm{u}_{\mathrm{i}} / 1 \leq \mathrm{i} \leq \mathrm{n}\right\}$

Hence, the total number of vertices $p=2 n+2$ and total number of edges $q=3 n$.

Here $p+q=5 n+2$.

Define a labeling f: V U E

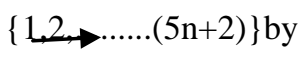

$$
\begin{aligned}
& \mathrm{f}(\mathrm{v})=2 \\
& \mathrm{f}(\mathrm{u})=1 \\
& \mathrm{f}\left(\mathrm{u}_{\mathrm{i}}\right)=2 \mathrm{i} ; 1 \leq \mathrm{i} \leq \mathrm{n} \\
& \mathrm{f}\left(\mathrm{v}_{\mathrm{i}}\right)=2 \mathrm{i}+1 ; 1 \leq \mathrm{i} \leq \mathrm{n} \\
& \mathrm{f}\left(\mathrm{e}_{\mathrm{i}}\right)=2 \mathrm{n}+2+\mathrm{i} ; 1 \leq \mathrm{i} \leq 3 \mathrm{n} .
\end{aligned}
$$

According to this pattern

$\operatorname{gcd}\{$ all the edges incident with $\mathrm{v}\}$

$$
\begin{aligned}
& =\operatorname{gcd}\{2 n+2+1,2 n+2+3,2 n+2+5, \ldots .2 n+2+(2 n-1)\} \\
& =\operatorname{gcd}\{2 n+3,2 n+5, \ldots \ldots .4 n+1\}=1
\end{aligned}
$$

$\operatorname{gcd}\{$ all the edges incident with $\mathrm{u}$ \}

$$
\begin{aligned}
& =\operatorname{gcd}\{2 n+2+2,2 n+2+4, \ldots \ldots, 2 n+2+2 n, 4 n+2+1, \\
& \quad 4 n+2+2, \ldots . .4 n+2+n\} \\
& =\operatorname{gcd}\{2 n+4,2 n+6, \ldots \ldots .4 n+2,4 n+3,4 n+4, \ldots \ldots \ldots .5 n+2\}=1 .
\end{aligned}
$$

$\operatorname{gcd}$ \{all the edges incident with vi\} 


\section{Available online at www.ijrat.org}

$$
=\operatorname{gcd}\{2 \mathrm{n}+1+2 \mathrm{i}, 2 \mathrm{n}+2+2 \mathrm{i}\}=1 \text { for } 1 \leq \mathrm{i} \leq \mathrm{n}
$$

$\operatorname{gcd}\left\{\mathrm{f}(\mathrm{v}), \mathrm{f}\left(\mathrm{v}_{\mathrm{i}}\right)\right\}=\operatorname{gcd}\{2,2 \mathrm{i}+1\}=1 ; 1 \leq \mathrm{i} \leq \mathrm{n}$

$\operatorname{gcd}\left\{\mathrm{f}\left(\mathrm{v}_{\mathrm{i}}\right), \mathrm{f}(\mathrm{u})\right\}=\operatorname{gcd}\{2 \mathrm{i}+1,1\}=1 ; 1 \leq \mathrm{i} \leq \mathrm{n}$

$\operatorname{gcd}\left\{\mathrm{f}(\mathrm{u}), \mathrm{f}\left(\mathrm{u}_{\mathrm{i}}\right)\right\}=\operatorname{gcd}\{1,2 \mathrm{i}\}=1 ; 1 \leq \mathrm{i} \leq \mathrm{n}$

Therefore, for each edge $e=u v$ the gcd of $\{f(u), f(v)$ is one and for each vertex, the gcd of all the incident edges is one. Therefore the splitting graph of a star graph $\mathrm{S}\left(\mathrm{K}_{1, \mathrm{n}}\right)$ is a total prime graph.

Example:

Total prime graph of splitting graph of a star graph $\mathrm{S}\left(\mathrm{K}_{1,4}\right)$

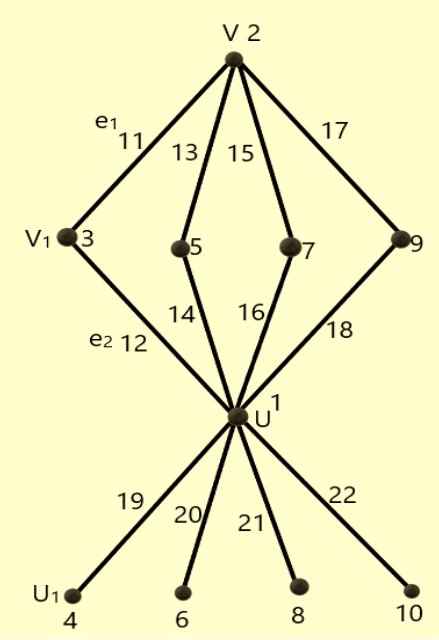

Theorem 2.7: The planter graph $R_{n}(n \geq 3)$ is total prime graph.

Proof:

Let $\mathrm{G}$ be a planter graph $\left(\mathrm{R}_{\mathrm{n}}\right)$

$$
\begin{aligned}
& V\left(R_{n}\right)=\left\{v_{1}, v_{2}, \ldots \ldots \ldots v_{n}, v_{n+1}, \ldots \ldots . . v_{2 n}\right\} \\
& E\left(R_{n}\right)=\left\{v_{1} v_{i+1} / 1 \leq i \leq n\right\} U\left\{v_{i} v_{n+2}\right\} U\left\{v_{n+1+i} v_{n+2+i} / 1 \leq i \leq n-2\right\} U \\
&\left\{v_{2 n} v_{1}\right\} .
\end{aligned}
$$

The total number of vertices $p$ is $2 n$ and total number of edges $q$ is $3 n-1 . p+q=5 n-1$.

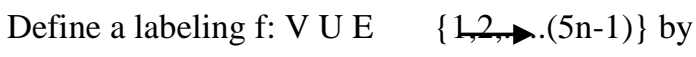

$$
\begin{aligned}
& \mathrm{f}\left(\mathrm{v}_{\mathrm{i}}\right)=\mathrm{i} ; 1 \leq \mathrm{i} \leq 2 \mathrm{n} \\
& \mathrm{f}\left(\mathrm{e}_{\mathrm{i}}\right)=2 \mathrm{n}+\mathrm{i} ; 1 \leq \mathrm{i} \leq 3 \mathrm{n}-1 .
\end{aligned}
$$

According to this pattern

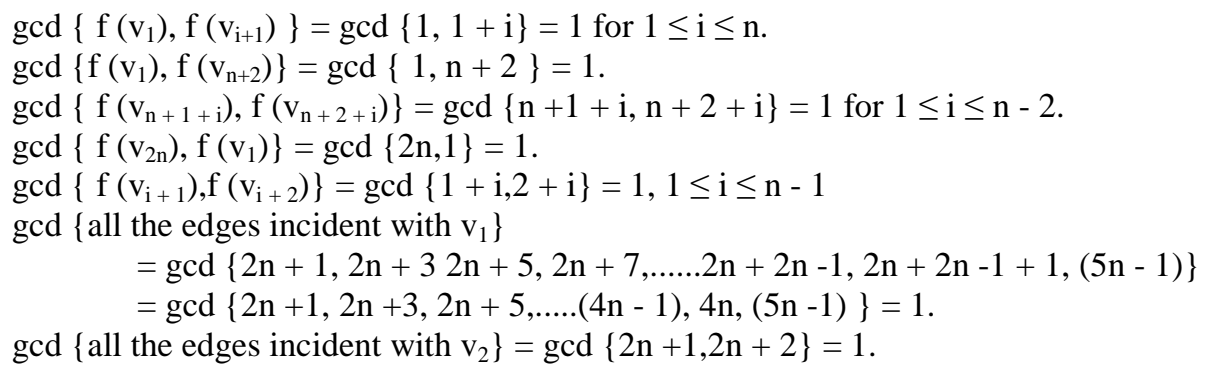




\section{Available online at www.ijrat.org}

$\operatorname{gcd}\left\{\right.$ all the edges incident with $\left.\mathrm{v}_{\mathrm{n}+1}\right\}=\operatorname{gcd}\{4 \mathrm{n}-2,4 \mathrm{n}-1\}=1$.

gcd $\left\{\right.$ all the edges incident with $\left.\left(\mathrm{v}_{\mathrm{n}+1+\mathrm{i}}\right)\right\}$

$$
=\operatorname{gcd}\{4 n-1+i, 4 n+i\}=1 \text { for } 1 \leq i \leq n-1
$$

gcd $\left\{\right.$ all the edges incident with $\left.v_{i+2}\right\}=$ gcd (incomplete)

Therefore, for each edge $e=u v$ the gcd of $\{f(u), f(v)\}$ is one and for each vertex, the gcd of all the incident edges is one. Therefore the planter graph $\left(\mathrm{R}_{\mathrm{n}}\right)$ is a total prime graph.

Example:

Total prime graph of planter graph $\left(\mathrm{R}_{4}\right)$

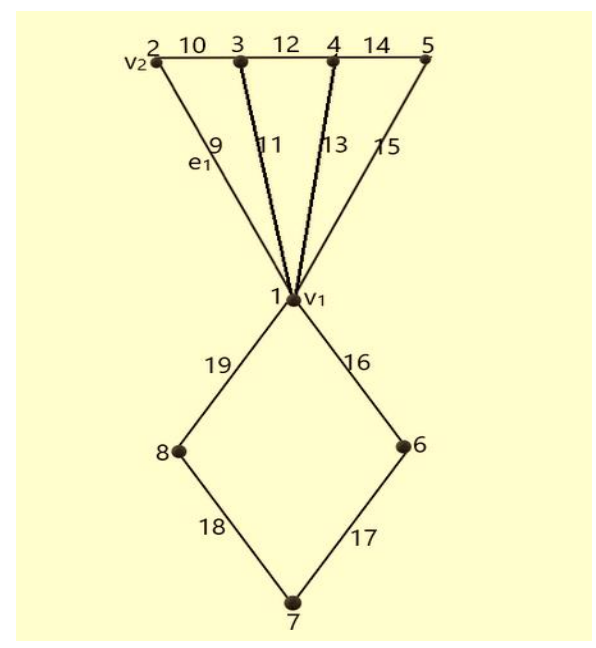

\section{REFERENCES}

[1] F. Harary. Graph Theory, Addison Wesley, Reading Mass 1972.

[2] A. Tout, A.N.Dabbouey and K. Howalla, Prime labeling of graphs. National Academy Science Letters, 11(1982), 365-368.

[3] T. Deretsky, S.M.Lee and J. Mitchem, on Vertex prime labeling of graphs in graph theory. Combinatorics and Applications Vol.I. J.Alavi, G.Chartrand and O.Ollerman and A.Schwank, eds... Proceedings $6^{\text {th }}$ International conference Theory and Application of Graphs (Wiley, Newyork, 1991) 359-369.

[4]. M. Ravi (a) Rama Subramanian, R.Kala. Total Prime Graph.International Journal of Computational Engineering Research (ijceronline.com), Vol2. Issue 5, ISSN (22503005) online, Sep.2012, Page 1588-1592.

[5] J.A. Gallian. A dynamic survey of graph labeling. Electronic J. combinatorics 17(2014).

[6]. C. Anathavalli, K. Nagarajan.Neighbourhood prime labeling for some special graphs. International Journal of Mathematics Archieve- 7(4), 2016, 224-230.

[7]. A Edward Samuel and S. Kalaivani. Prime labeling for some planter related graphs. International Journal of Mathematics Research,
ISSN 0976-58540, Vol. 8, Nov.3, (2016), pp 221-231.

[8]. S. Ashok kumar and S. Maragathavalli. Prime labeling of special graphs. IOSR, Journal of Mathematics (IOSR-JM), Vol.11 (2015), pp 01-05.

[10] S.K. Vaidya and K.K. Kanani. Prime labeling for some cycle related graphs. Journal of Mathematics Research. Vol.2, No. 2010.pp. 98-103.

[11] S. Meena and K. Vaithilingam. Prime labeling for some helm related graphs. International Journal of Innovative Research in Science, Engineeringand Technology, 2(4)(2013).

[12] S.K. Vaidya and Udaya M. Prajapati. Some new results on prime graph. Open Journal of Discrete Mathematics. (2012), 99-104

[13]. S. Meena and K. Vaithilingam. Prime Labeling for some Crown Related Graphs, International Journal of Scientific and Technology Research. Vol.2, Issue 3(2013), 92-95.

[14]. S.K. Vaidya and Udayan M. Prajapati. Some Results on Prime and 'K-Prime' L 